Series on Manufacturing Systems and Technology -Vol. 3

\title{
Fundamentals of Robotic
}

\section{Grasping and Fixturing}

\section{Caihua Xiong \\ Han Ding \\ Youlun Xiong}

Huazhong University of Science \& Technology, China 


\section{Published by}

World Scientific Publishing Co. Pte. Ltd.

5 Toh Tuck Link, Singapore 596224

USA office: 27 Warren Street, Suite 401-402, Hackensack, NJ 07601

UK office: 57 Shelton Street, Covent Garden, London WC2H 9HE

\section{British Library Cataloguing-in-Publication Data}

A catalogue record for this book is available from the British Library.

\section{FUNDAMENTALS OF ROBOTIC GRASPING AND FIXTURING Series on Manufacturing Systems and Technology - Vol. 3}

Copyright (c) 2007 by World Scientific Publishing Co. Pte. Ltd.

All rights reserved. This book, or parts thereof, may not be reproduced in any form or by any means, electronic or mechanical, including photocopying, recording or any information storage and retrieval system now known or to be invented, without written permission from the Publisher.

For photocopying of material in this volume, please pay a copying fee through the Copyright Clearance Center, Inc., 222 Rosewood Drive, Danvers, MA 01923, USA. In this case permission to photocopy is not required from the publisher.

ISBN-13 978-981-277-183-4

ISBN-10 981-277-183-2

Printed in Singapore. 


\section{Preface}

It is known that robotic grasping and fixturing (RGF) are important manipulations which contribute greatly to the production quality, cycle time, and cost in manufacturing, assembly and other industrial fields. The goals of both robotic grasping and fixturing are to immobilize kinematically an object by means of a suitable set of contacts. However, from the viewpoint of forces, there are essential differences between robotic grasping and fixturing. The ultimate difference lies in the fact that all of the robot fingers are active end-effectors, whereas all of the fixture locators are passive elements and only clamps can be considered to be active. The robotic grasping emphasizes the grasping closure and stability, whereas the robotic fixturing focuses on the localization accuracy of workpiece besides fixturing closure and stability. The primary goal of this book is to provide readers a fundamental knowledge of transforming the experience based design into the science based design for the robotic grasping and fixturing systems.

In order for RGF manipulation to become a science rather than an art, the content of the book is uniquely designed for a thorough understanding of the RGF from the multifingered robot hand grasp, basic fixture design principle, and evaluating and planning of robotic grasping/fixturing, and focuses on the modeling and applications of the RGF. This book is intended to be a reference text for academic researchers, manufacturing and industrial engineers. It may also be used as a text book for engineering graduate students in the discipline.

The authors of this book have worked on RGF for years. The contents of the book mostly come from the authors' recent work summary as well as some other people's contribution in the field. The book provides readers an overall picture and scientific basis of RGF.

The authors hope that this book can provide the comprehensive information and mathematic models of developing and applying grippers and fixtures in industry, and present long term valuable essential information for the academic researchers who are interested in robotic manipulation as a good reference.

This book is organized as follows. Chapter 1 describes the essential characteristics, similarities and differences between both of robotic grasping and fixturing, and the applications of RGF. Chapter 2 analyzes the grasping/fixturing closure. Chapter 3 discusses the grasping stability. Chapter 4 develops a fast and efficient force planning method to obtain the desired joint torques which will allow multifingered hands to firmly grasp an object with arbitrary shape. Chapter 5 addresses the problem of grasp capability analysis of multifingered 
robot hands. Chapter 6 analyzes the existence of the uncontrollable grasping forces (i.e., passive contact forces) in enveloping grasp or fixturing, and formulates a physical model of compliant enveloping grasp. Chapter 7 derives the kinematic equations of pure rolling contact over the surfaces of two contacting objects, and develops a direct force control method based on the position control for robotic manipulation systems. Chapter 8 discusses the dynamic stability of a grasped/fixtured object, and presents a quantitative measure for evaluating dynamically grasps. Chapters 9 and 10 describe the applications of fundamentals of RGF. In Chapter 9, a mapping model between the error space of locators and the workpiece locating error space is built up for 3D workpieces. Chapter 10 describes that deformations at contacts between the workpiece and locators/clamps resulting from large contact forces cause overall workpiece displacement, and affect the localization accuracy of the workpiece. This chapter defines the minimum norm of the elastic deformation at contacts as the objective function, and formulates the problem of determining of the optimal clamping forces as a constrained nonlinear programming which guarantees that the fixturing of the workpiece is force closure.

The research works in this book have been supported by the National Natural Science Foundation of China, the '973' National Basic Research Program of China (Grant No. 2005CB724100), the '863' Hi-Tech Research and Development Program of China, and the Program for New Century Excellent Talents in University (NCET-05-0651). We would like to thank Dr. Jürgen Leopold at The Fraunhofer Institute for Machine Tools and Forming Technology in Germany, Prof. Kevin Y. Rong at Worcester Polytechnic Institute in USA, Prof. Michael Y. Wang at The Chinese University of Hong Kong, and Prof. Y. F. Li at The City University of Hong Kong for helpful discussion. We would also like to thank Mr. Steven Patt and Ms. Rebecca Fu at World Scientific for their support in the production of this book. Sincere thanks also go to Mr. Wenbin Chen and Mr. Farong Gao for typesetting and proofreading of this book. 


\section{Contents}

Preface $\quad$ v

Chapter 1 Robotic Grasp and Workpiece-Fixture Systems

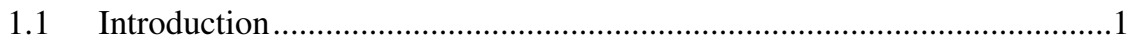

1.2 Robotic Manipulation and Multifingered Robotic Hands ..........................1

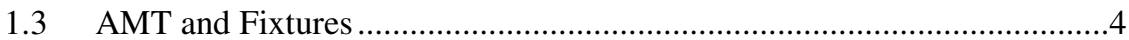

1.4 Comparison between Grasping and Fixturing .........................................

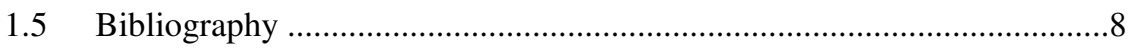

Chapter 2 Qualitative Analysis and Quantitative Evaluation of Form-Closure Grasping/Fixturing

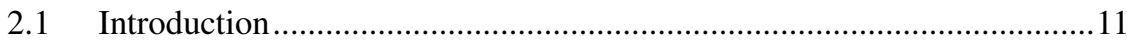

2.2 Qualitative Analysis .......................................................................13

2.2.1 Kinematic Characteristics of Grasping/Fixturing........................13

2.2.2 Discriminances of Form-Closure Grasping/Fixturing .................16

2.2.3 Minimum Number of Contacts with Frictionless ........................17

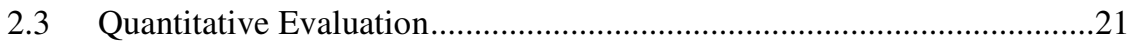

2.3.1 Evaluation Criteria ………………………............................21

2.3.2 Numerical Example.................................................................22

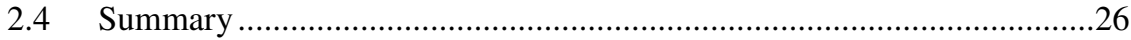

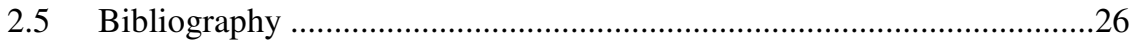

Chapter 3 Stability Index and Contact Configuration Planning of Force-Closure Grasping/Fixturing

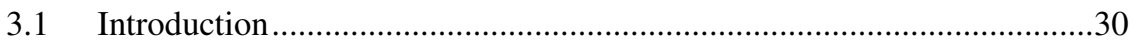

3.2 Description of Contacts with Friction ...................................................31 


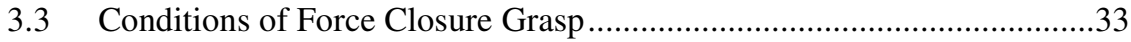

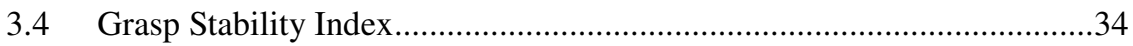

3.4.1 Definition of the Grasp Stability Index ………….......................34

3.4.2 Some Properties of the Index .....................................................36

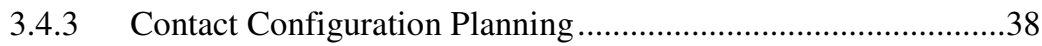

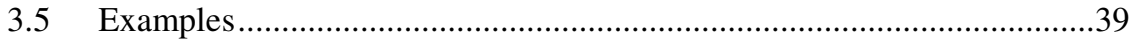

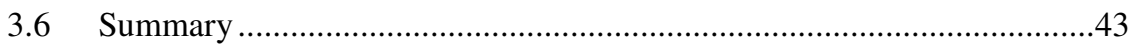

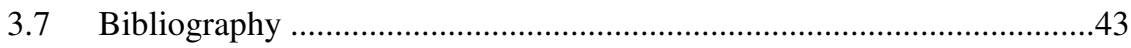

Chapter 4 Active Grasp Force Planning

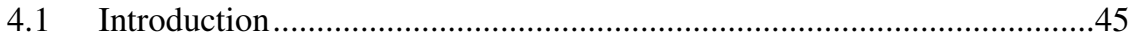

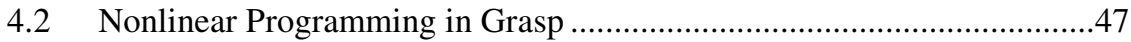

4.3 Force Planning Using Neural Networks................................................49

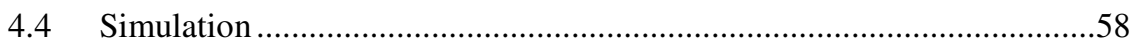

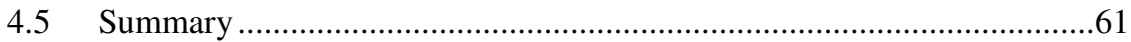

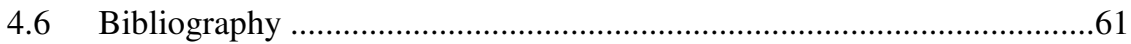

\section{Chapter 5 Grasp Capability Analysis}

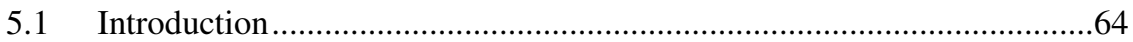

5.2 Evaluation of Multifingered Grasp Capability .....................................66

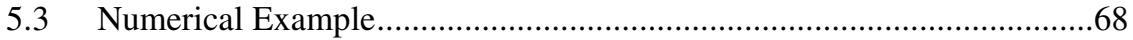

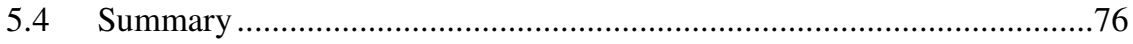

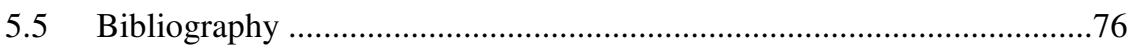

\section{Chapter 6 Compliant Grasping with Passive Forces}

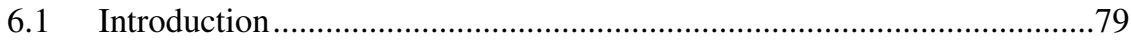

6.2 The Model of Compliant Grasping/Fixturing .......................................82

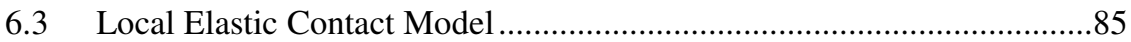

6.4 Deformation Compatible Constraints for All Contacts ...........................88

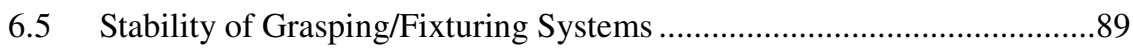




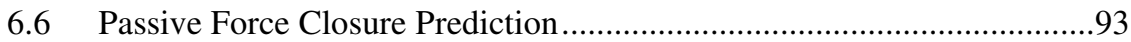

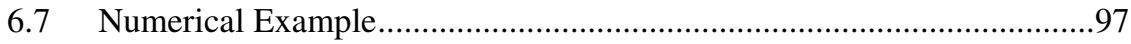

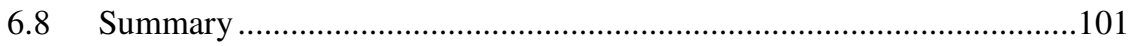

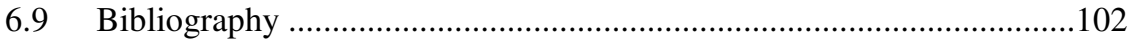

\section{Chapter 7 Kinematics of Contacts and Rolling Manipulation}

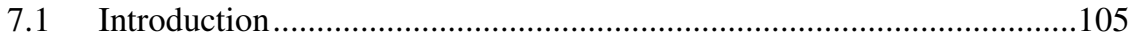

7.2 Kinematics of Pure Rolling Contact....................................................106

7.3 Kinematics of Manipulation with Rolling Contact .................................113

7.4 Coordinating Manipulation of Multifingered Robotic Hands .................116

7.4.1 Classification of Grasp Phases ................................................116

7.4.2 Coordinating Manipulation Strategy ……...............................116

7.5 Adjustment of Fingertip Contact Forces .............................................117

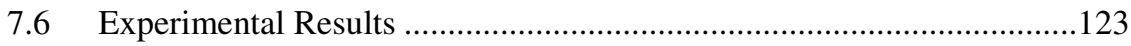

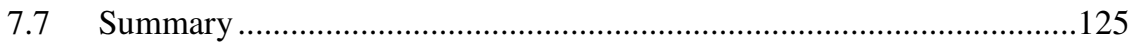

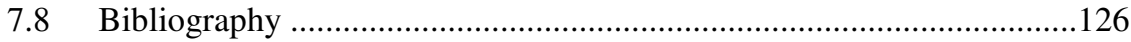

\section{Chapter 8 Dynamic Stability of Grasping/Fixturing}

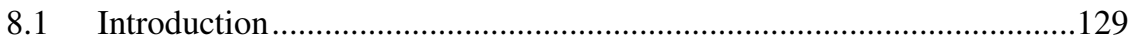

8.2 Dynamic Equations of Motion for a Grasped/Fixtured Object ..............130

8.3 Dynamic Stability Conditions and Quality Measure...............................135

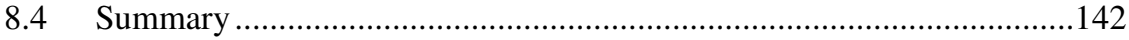

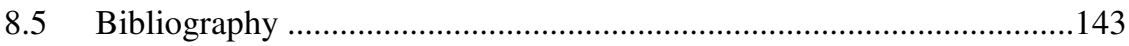

Chapter 9 Locating Error Analysis and Configuration Planning of Fixtures

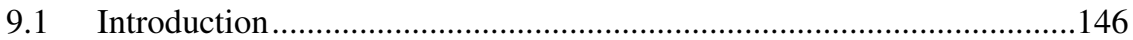

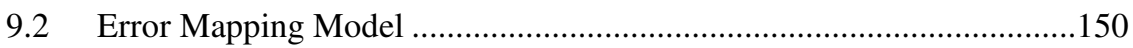

9.2.1 Fully Constrained Localization .................................................154

9.2.2 Over Constrained Localization..................................................154

9.2.3 Under Constrained Localization.............................................154 
9.3 Locator and Clamp Configuration Characteristics ..................................159

9.3.1 Locator Configuration Characteristics .....................................159

9.3.2 Clamp Configuration Characteristics ......................................159

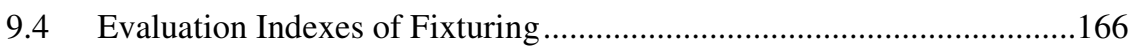

9.4.1 Evaluation Index of Locator Configurations .............................166

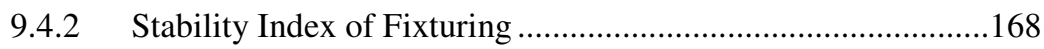

9.4.3 Fixturing Resultant Index .......................................................169

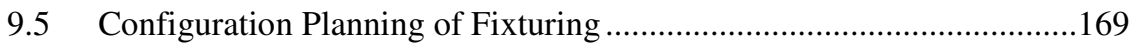

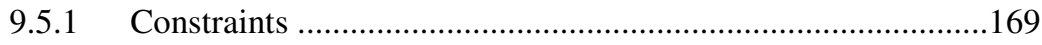

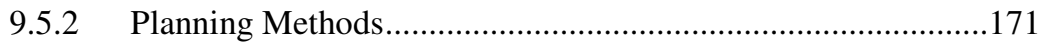

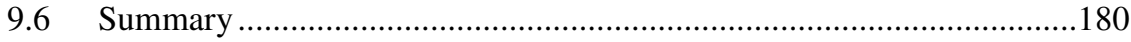

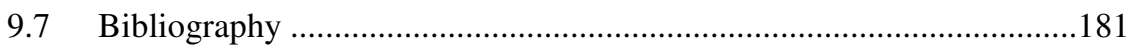

\section{Chapter 10 Clamping Planning in Workpiece-Fixture Systems}

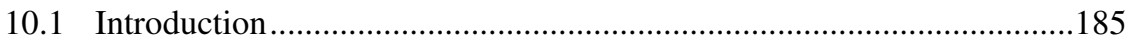

10.2 Planning of Magnitudes and Positions of Clamping Forces...................188

10.2.1 Objective Function ..................................................................188

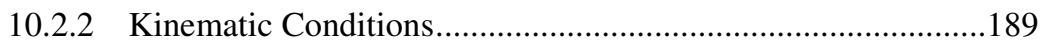

10.2.3 Solution of Optimal Clamping Forces.......................................191

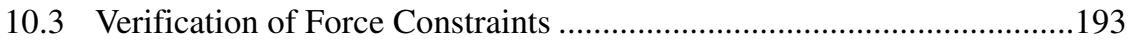

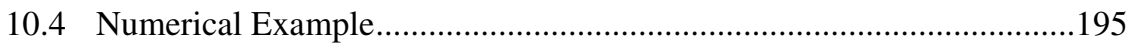

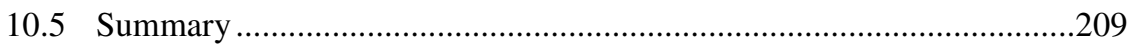

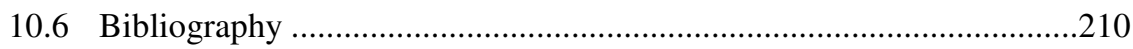

$\begin{array}{ll}\text { Index } & 215\end{array}$ 